\title{
INTEGRATING TOTAL PRODUCTIVE MAINTENANCE \& TOTAL QUALITY MANAGEMENT: CASE STUDY IN PAVEMENT BLOCK INDUSTRY
}

\author{
Kwadwo Appiah Boateng', Matthew Amissah ${ }^{2}$, Owusu Sekyere Boateng ${ }^{3}$ \\ ${ }^{1}$ Lecturer, Department of Civil Engineering, Sunyani Polytechnic, Sunyani, Ghana \\ kappiccuss@yahoo.com \\ ${ }^{2}$ Graduate Research Assistant, Department of Eng. Mngt, University of Old Dominion, USA \\ kabioshi@gmail.com \\ ${ }^{3}$ Engineer, Planning Department, Goldfields Ghana Limited, Tarkwa, Ghana \\ appiboat1982@gmail.com
}

\begin{abstract}
In this modern age of manufacturing, dynamism in manufacturing calls for lower cost of production, faster delivery, higher quality and customer satisfaction. Therefore the need for instituting various appropriate techniques and strategies to streamline manufacturing processes has become paramount for managers. Bearing in mind this priority demands, techniques such as Total Productive Maintenance (TPM), Total Quality Management (TQM), Just-In-Time Manufacturing (JIT) and Synchronous Manufacturing have gained popularity in the recent past. TPM as maintenance strategy is a comprehensive strategy, hence integrating it with TQM makes the approach more versatile and flexible. The objectives of both TPM and TQM are both geared towards enhancing the availability and the presentation of equipment continuously as a means of achieving the maximum effective performance, as well as ensuring that producing quality products become a hallmark. This paper seeks to evaluate the significance of implementing total productive maintenance (TPM) in a total quality management (TQM) environment in the maintenance function of manufacturing. The study establishes that integrating TPM and TQM strategically over a period of time can contribute to significant increases in the Overall Equipment Effectiveness (OEE) of machines thereby contributing towards realistic gains in productivity and manufacturing performance enhancements.
\end{abstract}

Keywords: Total Productive Maintenance, Total Quality Management, Overall Equipment Effectiveness, Availability, and Performance Rate

\section{INTRODUCTION}

Total Productive Maintenance (TPM) is a world class maintenance strategy that involves every member of an organization working cohesively in tandem to increase equipment effectiveness. Successful implementation of TPM relies on shared responsibility, natural work groups and full employee participation [1].

[2], known as the father of TPM, defines TPM as an innovative and systematic approach of maintenance that eliminates breakdowns by promoting autonomous maintenance by workers through their everyday activities [3, 4].

\subsection{Elements of Total Productive Maintenance}

TPM is characterized by elements such as:

- Maximization of the Overall Equipment Effectiveness

- Development of a reliable and maintainable productive maintenance

- Creation of an enabling environment that involves all departments of an organization
- The involvement of all employees of an organization form senior management to the lower ranks

- The promotion of TPM through small group activity and practice of autonomous maintenance [5].

Total Productive Maintenance implementation is geared towards ensuring that maintenance function and production are brought together with a comprehensive combination of sound reasonable practices, mutual team work and continuous improvement [6].

TPM is seen as a new application of TQM which has an aim to equip operators to develop their machinery for work by sensitizing the operators to develop ownership of their respective machines so that the culture of problem diagnostic and continuous improvement would be brought to bear and reflect in their day to day activities [7].

According to [8] the conceptual structure of TPM is founded on eight pillars namely:

1) Autonomous maintenance

2) Focused Improvement (Improve OEE)

3) Office TPM 
4) Education and training

5) Future equipment design

6) Planned maintenance

7) Safety, health and environment

8) Quality maintenance

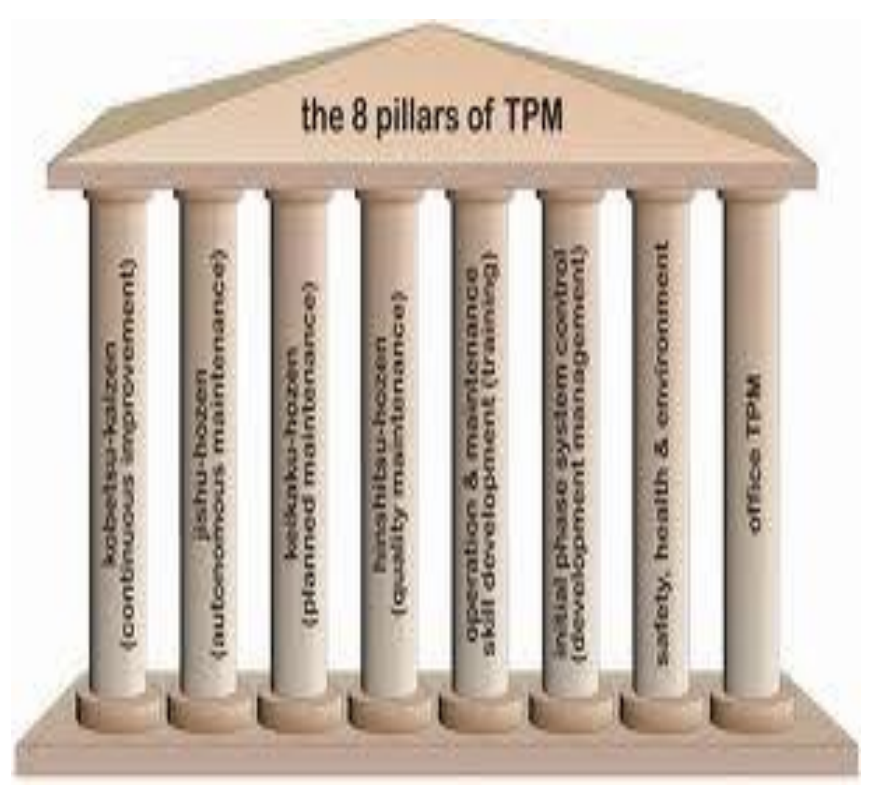

Fig.1.1: Eight pillar structure of TPM [9]

\subsection{Overall Equipment Effectiveness}

Overall Equipment Effectiveness (OEE) a principal metric of TPM ties the big six losses namely; equipment failure, reduced speed, setup and adjustment, small stops, production reject and start up rejects to measurables namely; availability, performance and quality. When we know the big six losses and the primary events contributing to the losses we can identify ways to monitor and correct them as a means of managing our assets [10]

\section{Availability}

Equipment availability refers to the amount of process time available for production. Equipment availability is affected by both unscheduled and scheduled downtime. Scheduled downtime such as set up and adjustment time as well as unscheduled downtime such as breakdowns reduces the available process time. In a well-functioning system the unplanned downtime is minimized whilst the planned downtime is optimized [1].

\section{Performance Rate}

The performance rate of equipment is typically optimized by operating equipment at its highest speed for the possible stipulated time therefore increasing the product through put tremendously. Performance rate is reduced by idle time and time lost due to minor stoppages [11].

\section{Quality Rate}

Quality rate identifies the actual quality products with respect to the total quantity of products produced. Efforts geared towards improving quality rate are necessary to be linked to critical requirements since products that are defective leads to a reduction in the quality rate [12]

\subsection{Total Quality Management}

\subsection{Quality Defined}

As the world continues to grow older in years and matures in all angles so does perceptions and the way people accept quality. Therefore it is very difficult to give a universal definition for quality [13].

Quality more often than not signifies the degree of excellence of a result be it a product or a service. The British brand "Rolls Royce" is known for its quality in all circles due to its acceptance by customers, hence customers cannot be left out in the definition of quality since invariably customers assess quality.

According to [14] quality can therefore be simply defined as meeting customer requirements and satisfaction.

\subsection{Quality Management}

"Total Quality Management" is an approach to improving competiveness, effectiveness and flexibility of a whole organization. It is an essential way of planning, organizing and understanding each activity and depends on each individual at each level" [14].

Total Quality Management is human centered and its main aim or objective is to continuously increase in satisfying customers at a continual real low cost. Total Quality Management should be viewed as a total system approach (not as an isolated program) and as a substantive part of a high level strategy. Total Quality works horizontally across all fundamental departments and functions, incorporates within each and every employee from high rank Chief Executive Officers to low rank Company Cleaners; stretches forward and backwards to include customer and supply chains [13].

\subsection{Contributions of quality philosophers}

Many quality philosophers have made their voices heard such as Genichi Taguchi, A.V. Feigenbaum and Kaoru Ishikawa but the most significant and important spearheading voices are:

- W. Edwards Deming

- Joseph Juran

- $\quad$ Philip B. Crosby

\section{Dr. W. Edwards Deming (1900-1993)}

Deming views variation as the chief under miner of achieving quality in an organization. Deming believed in facts and not speculation by people.

As a means of reducing variation Deming employed a never ending cycle of product service design, manufacture, test and sales followed by market surveys, redesign and improvement. 
He emphasized and reiterated that higher quality gives higher production which eventually leads to long term competitive strength. Deming philosophy places emphasis on top management spearheading continuous improvement in product and service quality by reducing variability and uncertainty in design, manufacturing and services processes [13].

Deming philosophy underwent a series of changes and modifications. His profound knowledge system consists of four (4) interrelated parts namely;

1. Application for system

2. Understanding of variation

3. Theory of knowledge

4. Psychology

\section{Dr. Joseph Juran (1904-2008)}

Juran proposed a definition for quality as; "fitness for use". His philosophy focused on three major quality processes, called Quality trilogy:

1. Quality Planning: Process of preparing to meet quality goals.

2. Quality control: The process of meeting quality goals during operations.

3. Quality improvement: process of breaking through exceptional unknown levels of performance.

\section{Dr. Philip Crosby (1926-2001)}

Crosby emphasizes a prevention rather than after-the-event inspection. He stressed on getting things right the first time. He came up with significant and important practices such as management responsibility for quality, employee recognition, management participation and cost prevention.

\subsection{Chapter Conclusion}

From the literature reviewed, it was identified that maintenance and quality management are very crucial success determinant factors for most manufacturing companies. Total productive Maintenance has been identified as a comprehensive approach that brings continuous improvement. [15] and has been established fundamental to quality management philosophies such as Total Quality Management [16].

It can be inferred from the literature reviewed that the two strategies TPM and TQM are geared towards continuous improvements in production.

\section{RESEARCH METHODOLOGY}

\subsection{Case Study at Cymain Block Industry}

The study was conducted at Cymain Block Industry and the values chosen are meant for justifying the research initiatives only. The company adapted TPM and TQM practices since $10^{\text {th }}$ November, 2010. Prior to their introduction, five selected machines were monitored and their respective Overall Equipment Effectiveness calculated. The same assessment was done six months after the introduction of TPM and TQM practices in their production set up.

\subsection{Assessing Production Machines by Using OEE Calculation}

The OEE of five pavement block machines LANG CC1, BURGER AG5, STR XL4, FODA JH3 and HINK XJ were calculated at a shift length of 16 hours for 5days. Microsoft spreadsheet was used as the standard format for the OEE calculation. Parameters such as shift length, down time, break time, ideal run rate, total and rejected pieces for each machine were fed to the programmed spreadsheet. The resulting Performance, Quality, Availability and Overall Equipment Effectiveness would be generated.

OEE is calculated by finding the product of the percentage availability, performance rate and the quality rate. Mathematically;

Overall Equipment Effectiveness (OEE) = Availability $\mathrm{x}$ Performance Rate x Quality Rate

Written as $\mathbf{O E E}=\mathbf{A} \times \mathbf{P} \times \mathbf{Q}$

Where $\quad \mathbf{A}=$ Availability

$\mathbf{P}=$ Performance

$\mathbf{Q}=$ Quality

Availability: This is a measure of the probability that an equipment will remain functional [13]. It is the fraction of the planned production time that the operation is available to operate and is mathematically expressed as:

\section{Availability $=$ Operating Time $/$ Planned Production Time}

Performance: This parameter takes into account speed losses (factors that cause the process to operate at less than the maximum possible speed when running). It is mathematically expressed as:

\section{Performance $=[$ Total Pieces $/$ Operating Time Rate $] /$ Ideal Time Rate}

Quality: Quality has a lot of definitions. It can be defined as the degree of conformance to set standards [13]. Quality rate is an expression of the ratio of good pieces to the total number of pieces produced [17]. It is mathematically expressed as: 


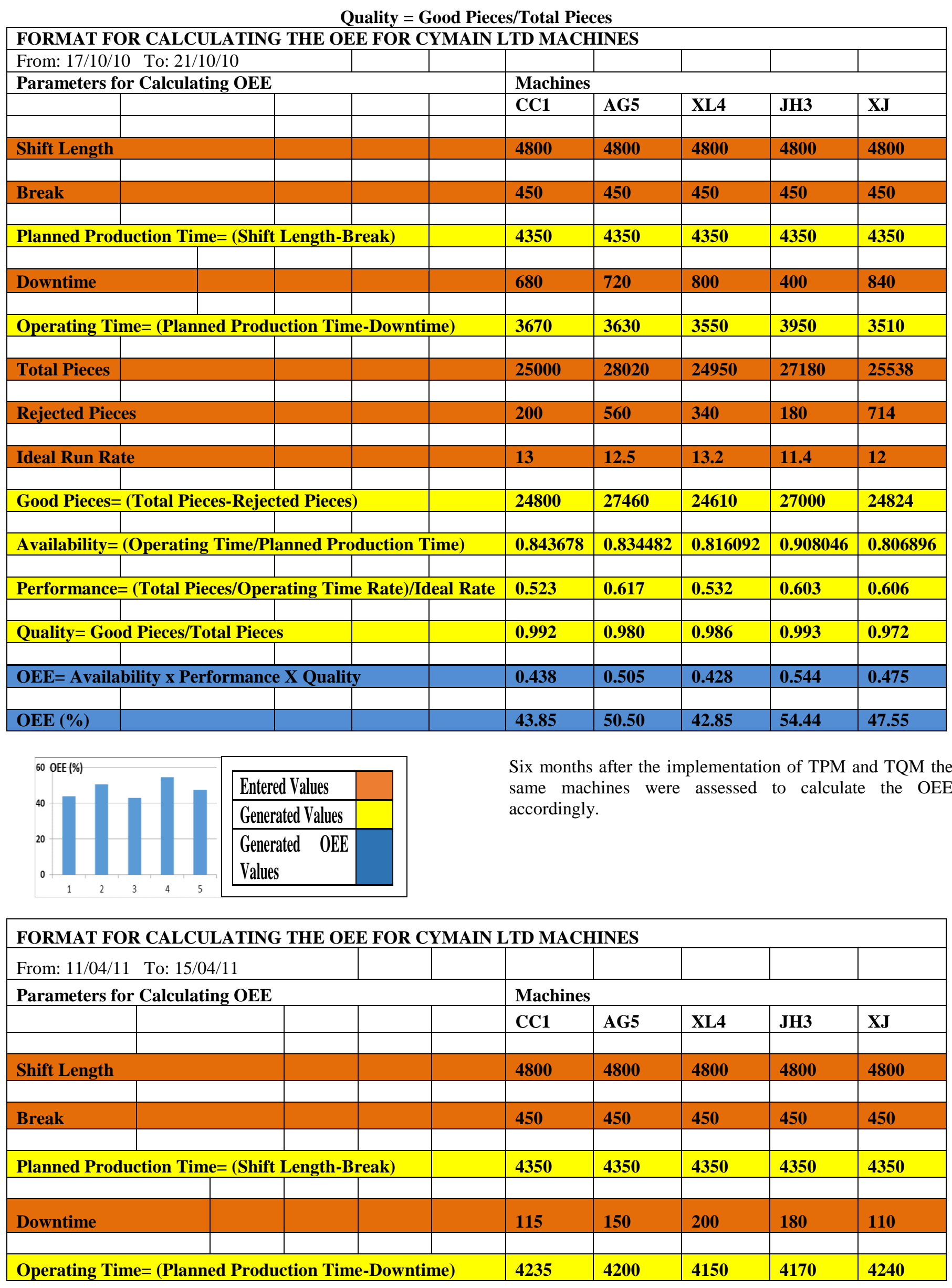




\begin{tabular}{|l|l|l|l|l|l|l|l|}
\hline \multicolumn{2}{|l|}{ Total Pieces } & & & & & & \\
\hline \\
\hline
\end{tabular}

\begin{tabular}{|l|l|}
\hline Entered & \\
Values & \\
\hline Generated & \\
Values & \\
\hline Generated & \\
OEE & \\
Values & \\
\hline
\end{tabular}

$$
\begin{aligned}
& 80 \\
& 75 \\
& 70 \\
& 65 \\
& 60
\end{aligned}
$$

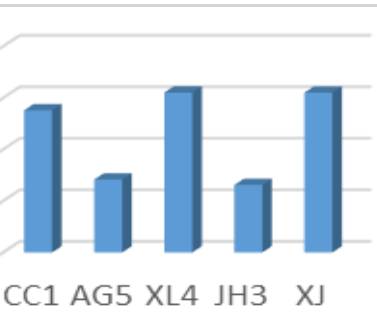

\section{CONCLUSION}

A pavement block industry has been studied and analyzed before and after the introduction of TPM \& TQM principles into the production line. It can be seen that the OEE of the machines showed significant rises after the six months; which is an indication of increases in machine availability, decrease in rework, rejection and increase in rate of performance. This reiterates the fact that both quality standard and preventive maintenance programme when well integrated can benefit an organization in its strive to achieve quality and productivity tremendously.

\section{REFERENCES}

[1]. Johnson, P. and Lesshammer, M. (1999) Evaluation and Improvement of Manufacturing Performance Measurement Systems: The role of OEE. International Journal of Operations and Production Management. 19(1) Pp 55-77

[2]. Nakajima, S. (1992) Total Productive Maintenance (TPM) Development Program, Productivity Press, M A. Cambridge.

[3]. Juran, J.M. and Gryna, F.M. (1993) Quality Planning and Analysis, $3^{\text {rd }}$ Edition, McGraw-Hill, New York.

[4]. Bhadury, B. (2000). "Management of productivity through TPM". Productivity, Volume 41, No. 2. pp. $240-51$.
[5]. Tywoniak, S., Rosqvist, T., Mardiasmo, O., \& Kivits, R. (2008) Towards the Integrated Perspective on fleet Asset Management: Engineering and Governance Considerations. Proceedings of $3^{\text {rd }}$ World Congress on Engineering Asset Management and Intelligent Systems

[6]. Cooke, F.L. (2000). "Implementing TPM in plant maintenance: some organizational barriers".International Journal of Quality \& Reliability Management. Vol. 17. No. 9, pp. 1003-16.

[7]. Chowdhury, C. (1995). "NITIE and HINDALCO give a new dimension to TPM". Udyog Pragati.Vol. 22, No. 1, pp. 5-11.

[8]. Dale, B.G., and Ireland, F. (2001) A study of Total Productive Maintenance Implementation, Journal of Quality in Maintenance Engineering, Vol. 7, No. 3, pp. 183-192

[9]. Ahuja, I. P. S. and Khamba, J. S., (2007). “An evaluation of TPM implementation initiatives in an Indian manufacturing enterprise". Journal of Quality in maintenance Engineering. Vol: 13, Issue 4.

[10].Ljungberg, O. (1998), "Measurement of overall equipment effectiveness as a basis for TPM activities", International Journal of Operations \& Production Management, Vol. 18 No. 5, pp. 495-507.

[11].Waeyenbergh, G. and Pintelon, L. (2002) A Framework for Maintenance Concept Development: International Journal of Production Economics. Pp 299313.

[12].Tsuchiya, S., (1992). Quality Maintenance: Zero Defects Through Equipment Management. Productivity Press, Cambridge, MA.

[13].Evans, R. J. \& Lindsay, M. W., (2005). The Management and control of Quality $6^{\text {th }}$ Edition. United States of America: Copyright by South Western

[14].Oakland, J.S. (1993) Total Quality Management $2^{\text {nd }}$ Edition. Nichols Publications Co 
[15].Johnston, R., Chambers, S., Harland, C. Harrison, A. and Slack, N. (1997) Cases in Operation Management. 2nd Edition. Pitman Publishing, London.

[16].Swanson, L. (2003) An Information-Processing Model of Maintenance Management. International Journal of Production Economics. 83(1), Pp 45-64.

[17].Vorne (2008) Calculating Overall Equipment Efficiency. Vorne Industries Inc., Illinois. [OnlineArticle:

http://www.oee.com/calculating_oee.html >]

\section{BIOGRAPHIES}

* K. Appiah Boateng obtained his Bachelor's degree in Civil Engineering from KNUST and Master's degree in Engineering Management from the University of Sunderland, U.K. He currently lectures at the Sunyani Polytechnic, Ghana.

* M. Amissah obtained his Bachelor's degree in Mechanical Engineering from KNUST and Master's degree in Engineering Management from the University of Old Dominion, U.S.A. He currently pursuing his Doctoral degree in the same University and is a Graduate Research Assistant at the Department of Engineering and Systems Management

* O. Sekyere Boateng obtained his Bachelor's degree in Mining Engineering from UMAT and He currently works as a Planning Engineer in Goldfields Ghana Ltd 